\title{
Exfoliation of smectite clays by branched polyamines consisting of multiple ionic sites
}

\author{
Chih-Wei Chiu ${ }^{\mathrm{b}}$, Chien-Chia Chu ${ }^{\mathrm{b}}$, Wen-Tung Cheng ${ }^{\mathrm{b}}$, Jiang-Jen Lin ${ }^{\mathrm{a}, *}$ \\ ${ }^{a}$ Institute of Polymer Science and Engineering, National Taiwan University, Taipei 10617, Taiwan \\ ${ }^{\mathrm{b}}$ Department of Chemical Engineering, National Chung Hsing University, Taichung 40227, Taiwan
}

Received 29 August 2007; received in revised form 23 November 2007; accepted 10 December 2007

Available online 23 December 2007

\begin{abstract}
Exfoliation through an ionic exchange reaction of layered silicate clays, including synthetic fluorinated mica (Mica) and natural montmorillonite (MMT), were achieved by using polyvalent amine salts as the intercalating agents. The requisite polyamine was synthesized from the epoxy/amine coupling reaction, involving a trifunctional poly(oxypropylene)-triamine ( ca. $440 \mathrm{~g} / \mathrm{mol} M_{\mathrm{w}}$ ) and diglycidyl ether of bisphenol-A. The polyamine was a mixture of oligomeric adducts consisting of multiple amine functionalities and a branched backbone. Partial acidification by $\mathrm{HCl}$ addition generated a series of amine salts that affected the intercalation and the expansion of the silicate interlayer in the range of 15.2-60.0 $\mathrm{X}$ XRD $d$ spacing. At the specific acidified ratio $\left(\mathrm{H}^{+} /\right.$amine $=1 / 3$ equiv ratio), the polyamine salts rendered the clay's layered structure into randomization. The result was confirmed by using XRD and transmission electronic microscopy (TEM). The hybrids of polyamines and Mica or MMT were blended into epoxy resins and cured into nanocomposites, which exhibited the improvements of thermal stability and hardness.
\end{abstract}

(c) 2007 Elsevier Ltd. All rights reserved.

Keywords: Intercalation; Exfoliation; Smectite clay; Poly(oxypropylene)-amine

\section{Introduction}

Organic modification of the naturally occurring smectite clays may lead these layered silicates to a variety of industrial applications including the uses as catalysts [1,2], adsorbents [3,4], biomaterial encapsulations [5,6], modified electrodes [7,8], and multilayer self-assembling substrates [9]. One of recent developments for utilizing the clay materials

\footnotetext{
${ }^{*}$ Corresponding author. Tel.: +88623366 5312; fax: +8862 33665237.

E-mail address: jianglin@ntu.edu.tw (J.-J. Lin).
}

is in the area of polymer/layered silicate nanocomposites [10]. In order to prepare a fine dispersion of silicates in hydrophobic polymers, organic surfactants are employed to improve their compatibility. The smectite clays, consisting of multiplelayered platelets in stacks and cationic metal ions in the interlayer spacing, are generally hydrophilic, easily swelled in water, but incompatible with most hydrophobic polymers. The organic modification through an ionic exchange reaction with organic quaternary salts, generally enlarge the clay layer spacing and organic compatibility. Conventionally, the organic cationic surfactants such as fatty 
ammonium salts [11-13], alkyl phosphonium salts [14-16], and polymeric ammonium salts [17-19] were used. The embedded organics may increase the clays' accessibility toward the incoming monomers or hydrophobic polymers. In the sequential process of preparing nanocomposites, the intercalated clays are in situ mixed and subsequently exfoliated into random platelets in the polymer matrices [20-22].

Among many kinds of smectite clays, montmorillonite (MMT) is the most studied and well characterized [23-26]. Similar to the montmorillonite clay, the synthetic fluorinated mica (Mica) has also a layered structure with ionic bridges in the primary stack, but with a larger platelet size than the $\mathrm{Na}^{+}$form of MMT. The difference is estimated to be 300 $1000 \mathrm{~nm}$ for Mica platelet units and $80-100 \mathrm{~nm}$ for MMT [27-29]. The previous studies have shown that Mica can be intercalated with organic surfactants, as to the MMT modification, but in a different XRD basal spacing. A wide expansion of silicate spacing by using the series of poly(oxypropylene)-diamine salts (POP-amine) in the molecular weight range of $230-5000 \mathrm{~g} / \mathrm{mol}$ has been achieved. However, the comparative results indicated a significant difference between the MMT and Mica intercalations with respect to the gallery expansion. For example, the use of the POP-amine of $5000 \mathrm{~g} / \mathrm{mol} M_{\mathrm{w}}$ could expand the interlayer structure of MMT up to $92.0 \AA$ XRD $d$ spacing, but only to $83.7 \AA$ for Mica $[27,30]$. The difference was attributed to the platelet size and steric hindrance for organics to embedding into Mica. Further investigations on the polymeric intercalating agents have included PP-g-MA, SEBS- $g$-MA, and SMA grafting amines and the Mannich types of polyamines [31-34].

In the article, we design a new class of polyamines with a branched backbone and multiple amine functionalities for the clay exfoliation. The polyamines were prepared from the epoxy/amine coupling reaction of diglycidyl ether of bisphenolA and POP-triamine of $440 \mathrm{~g} / \mathrm{mol} M_{\mathrm{w}}$. It is anticipated that the multiplicity of polyvalent ionic sites will efficiently affect the clay modification. In this study, we compare the effectiveness of the polyamine salts on the MMT and Mica exfoliation. The polyamine modified silicates are further mixed and cured with an epoxy system to yield the MMT and Mica nanocomposites. The physical properties including thermal stability and hardness were measured and correlated with the platelet dispersion in the polymer matrix.

\section{Experimental}

\subsection{Materials}

The synthetic fluorinated mica (Mica, SOMASIF ME-100) is a layered silicate clay with chemical analyses of $\mathrm{Si}(26.5 \mathrm{wt} \%), \mathrm{Mg}(15.6 \mathrm{wt} \%), \mathrm{Al}$ $(0.2 \mathrm{wt} \%), \mathrm{Na}(4.1 \mathrm{wt} \%), \mathrm{Fe}(0.1 \mathrm{wt} \%)$, and $\mathrm{F}$ $(8.8 \mathrm{wt} \%)$ and a cationic exchange capacity (CEC) of 120 mequiv/100 g, obtained from CO-OP Chemical Co. (Japan). The Mica is possibly swelled and modified by organic amine salts. In contrast, the naturally occurring micas cannot be easily swelled or organically intercalated due to their high platelet size and the inherent hydroxyl crosslinking. Sodium montmorillonite $\left(\mathrm{Na}^{+}-\mathrm{MMT}\right)$, a layered silicate clay with a cationic exchange capacity (CEC) of 115 mequiv/100 g, was supplied from Nanocor Co. Poly(oxypropylene)-triamine (Jeffamine ${ }^{\circledR}$ T403, abbreviated as T403) with a molecular weight of $440 \mathrm{~g} / \mathrm{mol}$ was purchased from Huntsman Chemical Co. or Aldrich Chemical Co. Diglycidyl ether of bisphenol-A (DGEBA, trade name BE-188) with an epoxy equivalent weight (EEW) of 188 was obtained from Nan-Ya Chemicals (Taiwan).

\subsection{Preparation of polyamines}

The typical experimental procedures for preparing the polyamines are described below. To a $50 \mathrm{~mL}$ three-necked and round-bottomed flask, equipped with a mechanical stirrer, a thermometer, and a heating mantle was placed with T403 (7.15 g) and DGEBA $(2.85 \mathrm{~g})$. The reactants were stirred by using a mechanical stirrer at room temperature. The progress of epoxy/amine reaction was monitored by FT-IR, showing the disappearance of $910 \mathrm{~cm}^{-1}$ epoxide absorbance during the process. The reaction was terminated after $4 \mathrm{~h}$ and the final product was recovered as a viscous, transparent liquid. The crude product after extracting out the unreacted T403 was analyzed by amine titration and GPC. The amine titration indicated the total-amine contents to be 4.8 mequiv/g. The GPC analysis identified two major peaks.

\subsection{Intercalation and exfoliation of Mica with the polyamine salts}

The ionic exchange reaction of Mica with a polyamine salt was performed according to the 
procedures reported previously [30]. An example of a preparative procedure for preparing the Mica exfoliation is described below. Synthetic fluorinated mica (Mica, CEC $=120$ mequiv $/ 100 \mathrm{~g}$, $1.0 \mathrm{~g}$ ) was dispersed in $100 \mathrm{~mL}$ of deionized water at $80^{\circ} \mathrm{C}$ by vigorously stirring. The prepared polyamines $(4.80 \mathrm{~g})$ and aqueous hydrochloric acid $(35 \mathrm{wt} \%, 0.75 \mathrm{~g})$ were mixed to form quaternary ammonium salts at room temperature and then poured into the Mica slurry in water. The mixture was continuously stirred at $80^{\circ} \mathrm{C}$ for $3 \mathrm{~h}$. The white precipitate was filtered, collected, and washed thoroughly with $40 \mathrm{~mL}$ of water/ethanol several times. The product was dried, pulverized into powder form and characterized by X-ray powder diffraction (XRD), thermal gravimetric analysis (TGA), and transmission electronic microscopy (TEM).

\subsection{Intercalation and exfoliation of $\mathrm{Na}^{+}-\mathrm{MMT}$}

Procedures similar to that of the Mica exfoliation were carried out. $\mathrm{Na}^{+}$-MMT $(\mathrm{CEC}=115 \mathrm{me}-$ quiv $/ 100 \mathrm{~g}, 1.0 \mathrm{~g}$ ) was dispersed in $100 \mathrm{~mL}$ of deionized water at $80^{\circ} \mathrm{C}$ by vigorously stirring for overnight. The prepared polyamines $(4.50 \mathrm{~g})$ and aqueous hydrochloric acid $(35 \mathrm{wt} \%, 0.71 \mathrm{~g})$ were mixed to form quaternary ammonium salts at room temperature and then poured into the MMT slurry in water. The mixture was stirred at $80^{\circ} \mathrm{C}$ for $3 \mathrm{~h}$, filtered, collected, and washed thoroughly with $40 \mathrm{~mL}$ of water/ethanol several times. The product was dried, pulverized into powder form and characterized by XRD, TGA, and TEM.

\subsection{Preparation of epoxy nanocomposites with the polyamine-Mica and MMT}

Epoxy nanocomposites were prepared by first dispersing the designated amount of the polyamine-clay with additional curing agent T403 by mechanical stirring for $1 \mathrm{~h}$ at $70{ }^{\circ} \mathrm{C}$ and optionally stirred under ultrasonic vibration. To the polyamine modified clays $(0.05,0.07$ or $0.1 \mathrm{~g})$ were mixed with T403 $(2.8 \mathrm{~g}, 6.3 \mathrm{mmol})$ and DGBEA $(7.2 \mathrm{~g}, 20 \mathrm{mmol})$. The mixture was thoroughly stirred, degassed and poured into a $1 / 8$-in.-thick flat aluminum mold to form a sample plaque. The curing process was conducted in an oven at the programmed conditions of $80^{\circ} \mathrm{C}$ for $2 \mathrm{~h}$ and $120{ }^{\circ} \mathrm{C}$ for $2 \mathrm{~h}$.

\subsection{Characterization}

Fourier transform infrared spectroscopy (FT-IR) was carried out using a Perkin-Elmer Spectrum One FT-IR spectrometer in the range of $400-4000 \mathrm{~cm}^{-1}$. Samples were prepared by dissolving in THF and evaporated into thin film on a $\mathrm{KBr}$ plate. Amine titration was estimated by using ASTM D2073-92 method. Relative molecular weights were analyzed on a gel permeation chromatography (GPC), Waters apparatus (515 HPLC pump, 717 autosampler, 2410 refractive index detector). A set of Waters Stygel columns was used under a THF flow rate of $1.0 \mathrm{~mL} / \mathrm{min}$, calibrated by polystyrene standards. The X-ray powder diffraction (XRD) was performed on a Schimadzu SD-D1 diffractometer with a $\mathrm{Cu}$ target $(\lambda=1.5405 \AA)$ at a generator voltage of $35 \mathrm{kV}$, a generator current of $30 \mathrm{~mA}$, and a scanning rate of $2 \% \mathrm{~min}$. The $d$ spacing $(n=1)$ was assigned on the basis of the Bragg's equation $(n \lambda=2 d \sin \theta)$. The thermal analyses were analyzed by using thermal gravimetric analyzer (TGA), on a Perkin-Elmer Pyris 1 model. The organic weight was estimated from the weight losses by ramping the temperature from 100 to $850^{\circ} \mathrm{C}$ at the rate of $10^{\circ} \mathrm{C} / \mathrm{min}$ in air. Transmission electronic microscopy (TEM) was performed on a Zeiss EM 902 A at an acceleration voltage of $80 \mathrm{kV}$, and the samples was cut into a wedge shape and then embedded in a polyethylene mold using epoxy resin. The specimen was trimmed into the shape of a trapezoid with a thickness of approximately $80 \mathrm{~nm}$ were microtomed at room temperature using a diamond knife on a Reichert-Jung Ultracut UCT, and collected on a 200 mesh carbon-coated $\mathrm{Cu}$ grid for the analyses. The glass transition temperature $\left(T_{\mathrm{g}}\right)$ was measured on Perkin-Elmer DSC 7, under the conditions of using a second heating scan at $10{ }^{\circ} \mathrm{C} / \mathrm{min}$ from 25 to $200{ }^{\circ} \mathrm{C}$. Pencil hardness was measured according to the method of ASTM D 3363-74.

\section{Results and discussion}

\subsection{Preparation of the polyamines}

The ionic exchanging agent was prepared from the amine/epoxy reaction of poly(oxypropylene)-triamine (T403) and diglycidyl ether of bisphenol-A (DGEBA), according to the reaction scheme and representative structures described in Scheme 1. This conventional amine/epoxy curing reaction may generate a cross-linked network. However, 


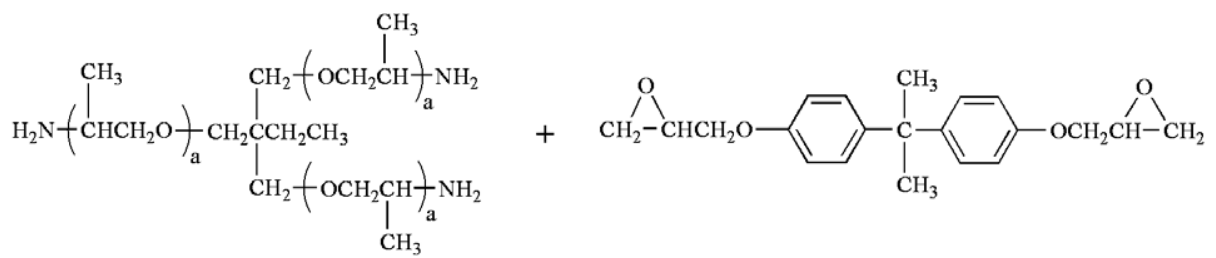

$\mathrm{T} 403\left(\mathrm{a}=4 \sim 5, M_{\mathrm{w}}=440\right)$

DGEBA

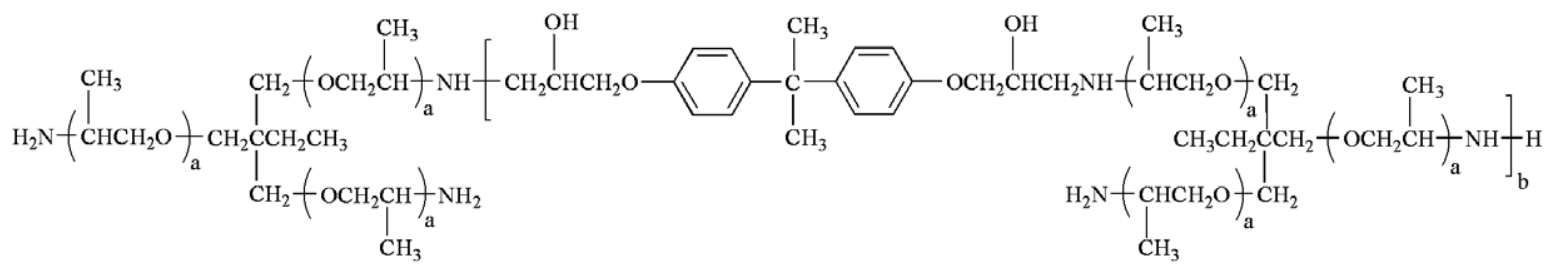

Branched polyamines $(b=1$ or 2$)$

Scheme 1. Representation of two possible polyamine structures from the amine/epoxy coupling reaction; the major product $(b=1$; six amine functionalities) and the minor product ( $b=2$; nine amine functionalities).

when the molar ratio of the T403/DGEBA starting materials at $2 / 1$ and $3 / 2$, a non-gelled and THF-soluble adduct was obtained. The analysis by amine titration, GPC, and FT-IR indicated the product was a mixture of polyamines. The possible structures of the adducts are illustrated to represent the multiple amine functionalities, generally consisting of secondary amines $\left(-\mathrm{CH}_{2} \mathrm{NH}-\right)$, primary amine terminals $\left(-\mathrm{NH}_{2}\right)$, poly(oxypropylene) segments and bisphenol-A linking sites. Besides two possible structures for the 2/1 T403/DGEBA adducts, other oligomers such as a dimer by linking the primary structure adduct with $1 \mathrm{~mol}$ of DGEBA may be existed.

\subsection{Ionic exchange reaction and exfoliation of Mica and MMT by polyamines}

The synthesized poly(oxypropylene)-polyamines/ DGEBA products are hydrophobic and insoluble in water. When treating with hydrochloric acid, the hydrophobic polyamines were converted into the corresponding water-soluble amine salts. Partial acidification could control the multiplicity of the reactive sites for the ionic exchanging intercalation with clay. By adjusting the $\mathrm{HCl} /$ amine equivalent ratios, the intercalated clays were analyzed by XRD and TGA, with results summarized in Table 1 .

The intercalation of Mica by the polyamines resulted the silicates of various XRD $d$ spacing
(15.2-60.0 $\mathrm{A})$. Ionic exchange reaction under the condition of $1 / 1 / 1$ molar ratio of polyamine $/ \mathrm{H}^{+} /$ CEC, the silicate with a low $15.2 \AA d$ spacing and $30 \mathrm{wt} \%$ organic fraction (TGA) was obtained. With increasing the acidification to the polyamine at the polyamine $/ \mathrm{H}^{+} / \mathrm{CEC}$ ratio of $1 / 2 / 1$, the intercalation afforded a hybrid of $38.9 \AA d$ spacing and an organic fraction of $58 \mathrm{wt} \%$. A further increase in $\mathrm{HCl}$ equiv to $1 / 3 / 1$ ratio could only shrink the spacing at $32.8 \AA$ and $c a .50 \mathrm{wt} \%$ organic embedment. However, by maintaining the acidification ratio at polyamine $/ \mathrm{H}^{+}=1 / 2$ but decreasing the Mica amount (i.e., polyamine $/ \mathrm{H}^{+} / \mathrm{CEC}$ at $1 / 2 / 0.5$ ), the resultant hybrid had a further enlargement of $d$ spacing at $60.0 \AA$ and organic fraction of $68 \mathrm{wt} \%$. For such a high platelet distance in the layered structure, it was noticed that their XRD peak patterns did obey the Bragg's equation $(n \lambda=2 d \sin \theta)$, with the observed peaks to be $n=2,3$, and 4 . However, the $n=1$ peak was out of the detection limit in the wide-angle XRD measurement. On the basis of the Bragg's assignment, the assumption of the starting peak in a series of peak pattern was made to be an arbitrary $n$ number. According to the corresponding $n$ series and its $\sin \theta$, the correct peak pattern should follow the Bragg's equation to have a constant $d$ value. In the example of Fig. 1, the assignment of the first peak to be $n=2$, the following peaks $n=3$ and 4 fitted well for the Bragg's equation to have the same $d$ spacing $(60.0 \AA)$. 
Table 1

Intercalation of Mica and MMT by polyamines of various multiple ionic sites

\begin{tabular}{|c|c|c|c|c|c|}
\hline \multirow[t]{2}{*}{ Intercalating agent } & \multirow[t]{2}{*}{ Polyamine $/ \mathrm{H}^{+} / \mathrm{CEC}^{\mathrm{a}}$ (molar ratio) } & \multicolumn{2}{|c|}{$d$ spacing $(\AA)^{\mathrm{b}}$} & \multicolumn{2}{|c|}{ Organics/Silicates $(\mathrm{w} / \mathrm{w})$} \\
\hline & & Mica & MMT & Mica & MMT \\
\hline \multirow[t]{5}{*}{ Polyamine } & $1 / 1 / 1$ & 15.2 & 18.8 & $30 / 70$ & $32 / 68$ \\
\hline & $1 / 2 / 1$ & 38.9 & 38.2 & $58 / 42$ & $58 / 42$ \\
\hline & $1 / 3 / 1$ & 32.8 & 33.3 & $50 / 50$ & $52 / 48$ \\
\hline & $2 / 4 / 1$ & 60.0 & Featureless & $68 / 32$ & $68 / 32$ \\
\hline & $3 / 6 / 1$ & Featureless & Featureless & $76 / 24$ & $76 / 24$ \\
\hline None & - & 12.6 & 12.4 & - & - \\
\hline
\end{tabular}

a Addition of $\mathrm{HCl}$ to polyamine; calculated on the basis of the titrated total-amine contents.

b X-ray $d$ spacing calculated on the basis of the Bragg's equation $(n \lambda=2 d \sin \theta)$.

${ }^{\mathrm{c}}$ Measured by TGA from 100 to $850^{\circ} \mathrm{C}$ at the rate of $10^{\circ} \mathrm{C} / \mathrm{min}$ in air.
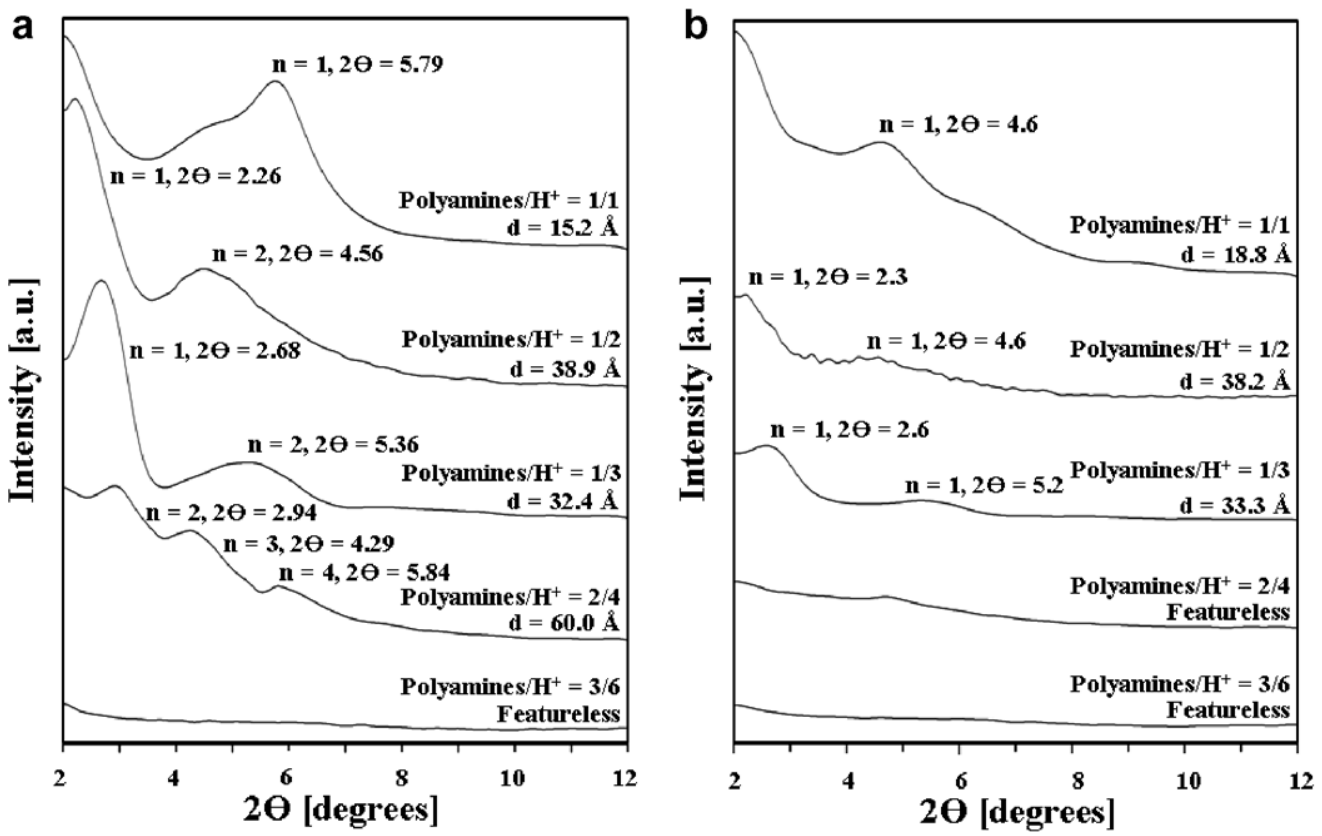

Fig. 1. X-ray diffraction patterns of (a) polyamines/Mica and (b) polyamines/MMT with various polyamines/ $\mathrm{H}^{+}$ratios.

Furthermore, it is noted that the appearance of multiple peaks of Bragg's pattern implies that the organic intercalation is in high regularity for expanding the basal distance between each pair of the neighboring platelets.

It was observed that the polyamine intercalation could further increase the platelet distance to the extent of featureless XRD pattern (none of peaks) implying a possible exfoliation of the layered structure. This was occurred when using the excess amount of polyamine salts or the molar ratio of polyamine $/ \mathrm{H}^{+} / \mathrm{CEC}=3 / 6 / 1$. Apparently, the polyamine was effective for the clay randomization. In order to generalize the effectiveness of the polyamine as an exfoliating agent, another clay $\left(\mathrm{Na}^{+}\right.$-
MMT) was subjected to the ionic exchange reaction. Initially, it was found to have $d$ spacing from $18.8 \AA, 38.2 \AA$, and $33.3 \AA$ at various polyamine/ $\mathrm{H}^{+} / \mathrm{CEC}$ ratios of $1 / 1 / 1,1 / 2 / 1$, and $1 / 3 / 1$. A featureless XRD pattern was observed at 2/4/1 ratio, under which condition the Mica intercalation yielded $60.0 \AA d$ spacing. It appears that the designed polyamine is actually effective for both MMT and Mica clays for the exfoliation.

\subsection{Mechanism for the exfoliation}

Through the $-\mathrm{NH}_{3}^{+} / \mathrm{Na}^{+}$exchange reaction, the polyamine salts may incorporate and tether onto the silicate platelet surface at multiple sites in the 
silicate confinement. With varied acidification ratios, the polyamine salts may possess different conformations or molecular shapes within the interlayer gallery. As illustrated in Fig. 2, the conceptual diagrams show the different distances between two neighboring silicate platelets generated by the same polyamines but with different $\mathrm{HCl}$ additions and the amount to CEC equiv; $d$ spacing of $15.2 \AA$ at $1 / 1 / 1$ of polyamine/ $\mathrm{H}^{+} / \mathrm{CEC}$ (Fig. 2a), $38.9 \AA$ at $1 / 2 / 1$ (Fig. 2b), $60.0 \AA$ at 2/4/1 (Fig. 2c), and featureless at 3/6/1 (Fig. 2d). Furthermore, the trend of $d$ spacing expansion is correlated to the amount of organic accumulation in the confinement, analyzed by TGA. The driving forces for the organic embedment may involve two types of bonding forces, ionic bridging of amine salts with platelet surface and self-aggregation of the hydrophobic polyamine backbones to generate a new phase through intermolecular non-covalent bonding. Ultimately, the phase segregation of the intercalating organics overcomes the ionic attraction originally existed between the neighboring silicate platelets.

\subsection{TEM evidence for the clay exfoliation}

The exfoliation of the Mica by the polyamines is further evidenced by the TEM observation. Under the condition of polyamine $/ \mathrm{H}^{+} / \mathrm{CEC}=3 / 6 / 1$, the hybrid exhibits a featureless XRD pattern, indicating a $d$ spacing larger than $100 \AA$ or beyond the detection limit. In the TEM micrographs (Fig. 3a and b), most of platelets appear to be well-dispersed and in a random distribution. There are few locations where existed 1-3 platelets in the manner of parallel alignment. By comparison, an intercalation of polyamine $/ \mathrm{H}^{+} / \mathrm{CEC}=2 / 4 / 1$ and $60.0 \AA d$ spacing exhibits the hybrid with their interlayer spacing in a highly regular or parallel structure (Fig. 3c and
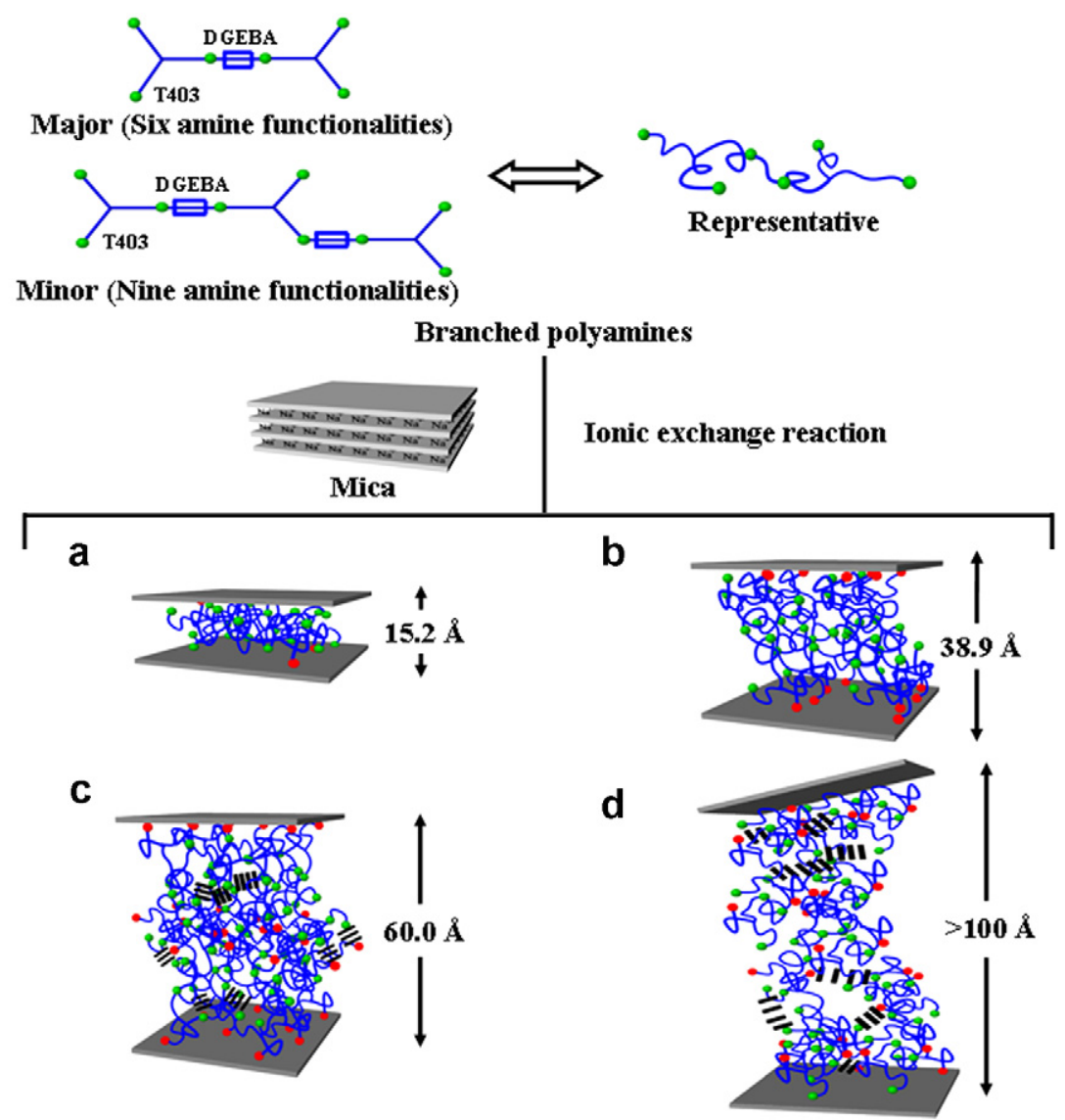

$\bullet:-\mathrm{NH}_{2}$ or $-\mathrm{NH}-\quad \bullet:-\mathrm{NH}_{3}{ }^{+}$or $-\mathrm{NH}_{2}{ }^{+} \quad$ 三: Intermolecular non-covalent bonding

Fig. 2. Conceptual illustration of polyamine intercalation and exfoliation of the silicate platelets (Mica), varied by using different molar ratios of polyamines/ $\mathrm{H}^{+} / \mathrm{CEC}$, at (a) $1 / 1 / 1$ (XRD $d$ spacing $=15.2 \AA$ ), (b) $1 / 2 / 1(38.9 \AA$ ), (c) $2 / 4 / 1$ (60.0 $\mathrm{A}$ ), and (d) $3 / 6 / 1$ (XRD featureless or $>100 \AA$ ). 

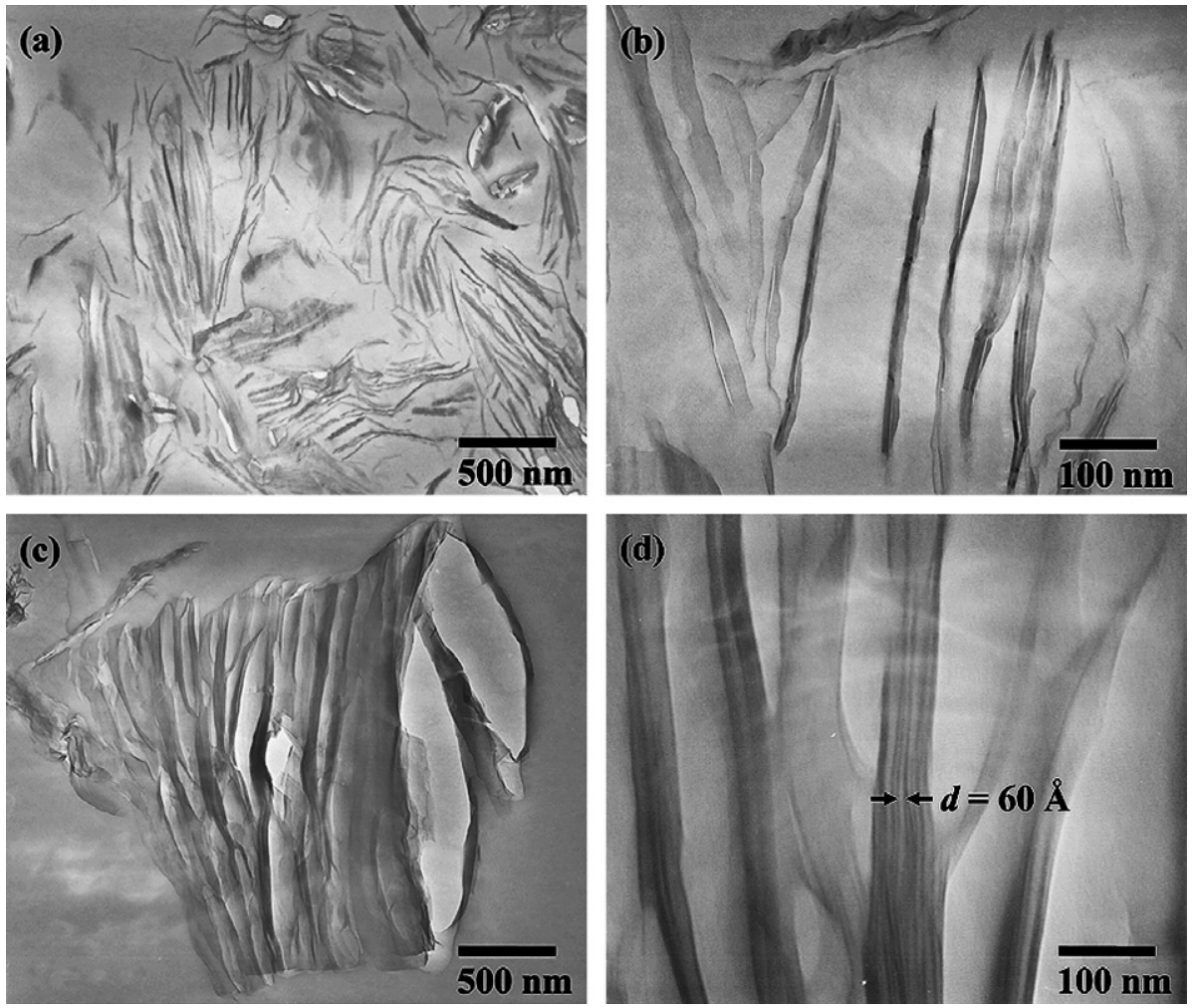

Fig. 3. TEM micrographs of ( $\mathrm{a}$ and $\mathrm{b}$ ) exfoliated silicates (Mica) from polyamine/ $\mathrm{H}^{+} / \mathrm{CEC}=3 / 6 / 1$, with featureless $\mathrm{XRD}$, (c and $\mathrm{d}$ ) intercalated silicates by polyamine $/ \mathrm{H}^{+} / \mathrm{CEC}=2 / 4 / 1$, with $\mathrm{XRD} d$ spacing $=60.0 \AA$.

d). A rough estimation of 8-12 parallel platelets in a stack can be observed, with a distance between the neighboring platelets similar to the XRD measurement $(60.0 \AA)$. However, the length of these silicate stacks, in some cases, is extended into 1-2 $\mu \mathrm{m}$ which is longer than the primary structure as observed to be $300-1000 \mathrm{~nm}$ in Fig. 3a and $300-400 \mathrm{~nm}$ in Fig. 3b. The morphology is explained by the formation of a secondary structure from the primary stacks.

\subsection{Properties of epoxy nanocomposites}

The nanocomposites were prepared by mixing the polyamine modified Mica or MMT with the two-component system of epoxy resin/T403 amine. As summarized in Table 2, the properties of thermal decompositions of the epoxy nanocomposites were analyzed by thermal gravimetric analysis (TGA). With a $1 \mathrm{wt} \%$ loading of the polyamine/clay hybrids, the resultant materials exhibited a slow decomposition rate or delayed degradation temperature. For the measurement of the initial $5 \mathrm{wt} \%$ weight loss $\left(T_{5 \mathrm{wt} \%}\right)$, the TGA trace indicated an
Table 2

Thermal and physical properties of polyamine modified clays cured with the epoxy resin and T403 curing agent into nanocomposites

\begin{tabular}{lllll}
\hline $\begin{array}{l}\text { Silicate } \\
\text { platelets }\end{array}$ & $\begin{array}{l}\text { Loading } \\
(\mathrm{wt} \%)^{\mathrm{a}}\end{array}$ & $\begin{array}{l}T_{5 \mathrm{wt} \%} \\
\left({ }^{\circ} \mathrm{C}\right)^{\mathrm{b}}\end{array}$ & $\begin{array}{l}T_{\mathrm{g}} \\
\left({ }^{\circ} \mathrm{C}\right)^{\mathrm{c}}\end{array}$ & $\begin{array}{l}\text { Hardness } \\
(\mathrm{H})^{\mathrm{d}}\end{array}$ \\
\hline None & 0 & 337 & 71 & 2 \\
Exfoliated Mica & 0.5 & 344 & 81 & 6 \\
& 0.7 & 347 & 80 & 7 \\
& 1 & 355 & 78 & 7 \\
Exfoliated MMT & 0.5 & 342 & 76 & 5 \\
& 0.7 & 346 & 76 & 6 \\
& 1 & 348 & 75 & 6 \\
\hline
\end{tabular}

${ }^{\text {a }}$ Calculated on the basis of silicate weight.

b $T_{5 \mathrm{wt} \%}$ : temperature of weight loss at $5 \mathrm{wt} \%$, measured by TGA from 100 to $850{ }^{\circ} \mathrm{C}$ at $10^{\circ} \mathrm{C} / \mathrm{min}$ in air.

${ }^{\mathrm{c}}$ Based on DSC measurements.

${ }^{\mathrm{d}}$ Pencil test.

increase from 337 to $355^{\circ} \mathrm{C}$ for the Mica and from 337 to $348{ }^{\circ} \mathrm{C}$ for the MMT additions. The presence of silicate hybrids slightly enhanced the thermal stability of these epoxy nanocomposites. On the basis of DSC measurements, the epoxies exhibited a higher glass transition temperature $\left(81^{\circ} \mathrm{C}\right.$ for Mica and $76^{\circ} \mathrm{C}$ for MMT) than that of the pristine epoxy 

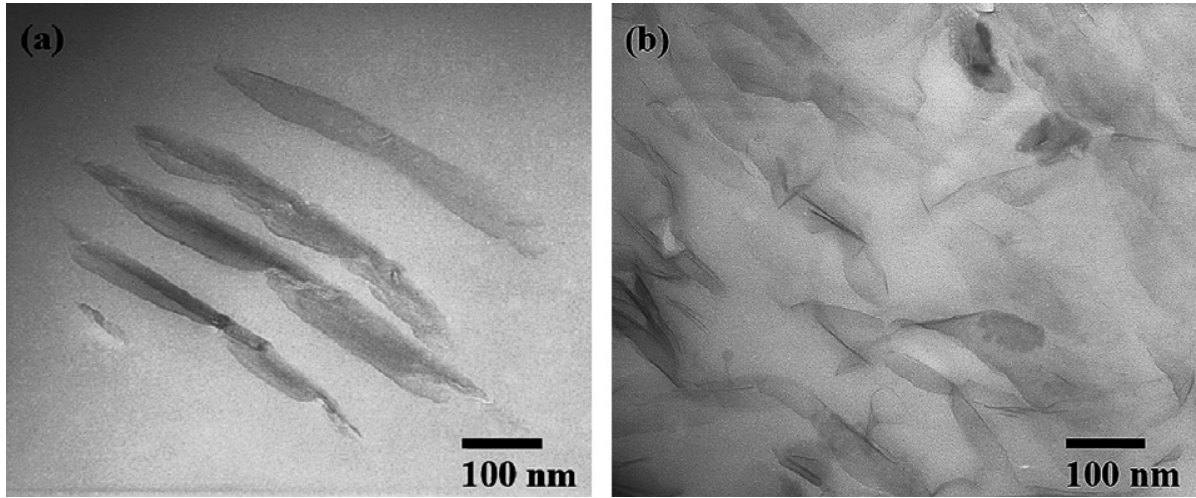

Fig. 4. TEM micrographs of $1 \mathrm{wt} \%$ exfoliated platelets in epoxies, (a) exfoliated Mica in epoxies; (b) exfoliated MMT in epoxies, at different magnifications.

$\left(71^{\circ} \mathrm{C}\right)$. Apparently, the $T_{\mathrm{g}}$ was slightly affected by the initial $0.5 \mathrm{wt} \%$ loading but leveled off for the higher loadings. The most significant contribution for the platelet addition is the material hardness enhancement. By loading only $1 \mathrm{wt} \%$ of silicate platelets, the epoxy nanocomposites showed an increase of hardness from $2 \mathrm{H}$ to $7 \mathrm{H}$ for Mica and to $6 \mathrm{H}$ for MMT. The enhancement is presumably affected by the intensive interaction between platelets and epoxies in the matrix.

\subsection{TEM observation of the exfoliated clays in epoxies}

The fine distribution of the exfoliated platelet in the epoxy matrix was evidenced by the TEM observation. In Fig. 4a and b, the homogeneous distribution of $1 \mathrm{wt} \%$ clay platelet in the amine-cured epoxy matrix loading is demonstrated. It is interestingly noted that, in Fig. 4a (Mica), the distribution of silicate platelets is actually in a parallel orientation rather than in a random single-platelet manner. By comparison, in the case of Fig. 4b (MMT), most of platelets are in a well-dispersed and random manner. It appears that the large platelets of Mica have a tendency for forming lamellar arrangements.

\section{Conclusion}

Layered silicates including the synthetic fluorinated mica and sodium montmorillonite were possibly exfoliated by using a synthesized polyamine with the controlled multiplicity of $-\mathrm{NH}_{3}^{+}$sites. The requisite polyamine was simply prepared from the Jeffamine T403/DGEBA coupling at a specific molar ratio. Their partially acidified polyamine salts enabled to ionic exchange and randomize the clay layered structures, evidenced by XRD and TEM. The result of randomization was attributed to the presence of the multiple ionic sites tethering onto the silicate platelets and twisting their conformation in the clay confinement. The exfoliated Mica and MMT platelets were blended into epoxies to form nanocomposites with significant improvements in physical properties, particularly the hardness.

\section{Acknowledgments}

We acknowledge the financial supports from National Science Council (NSC) and the Ministry of Economics Affairs (Taiwan).

\section{References}

[1] Feng J, Hu X, Yue PL. Environ Sci Technol 2004;38:269-75.

[2] Stackhouse S, Coveney PV, Sandre E. J Am Chem Soc 2001;123:11764-74.

[3] Liu W, Gan J, Papiernik SK, Yates SR. J Agr Food Chem 2000;48:1935-40.

[4] Schulz JC, Warr GG. Langmuir 2000;16:2995-6.

[5] Lin JJ, Wei JC, Juang TY, Tsai WC. Langmuir 2007;23:1995-9.

[6] Choy JH, Kwak SY, Jeong YJ, Park JS. Angew Chem Int Edit 2000;39:4041-5.

[7] Fendler JH. Chem Mater 1996;8:1616-24.

[8] Eckle M, Decher G. Nano Lett 2001;1:45-9.

[9] Umemura Y, Yamagishi A, Schoonheydt R, Persoons A, Schryver FD. J Am Chem Soc 2002;124:992-7.

[10] Ray SS, Okamoto M. Prog Polym Sci 2003;28:1539-641.

[11] Vaia RA, Teukolsky RK, Giannelis EP. Chem Mater 1994:6:1017-22.

[12] Klapyta Z, Fujita T, Iyi N. Appl Clay Sci 2001;19:5-10.

[13] Yang JH, Han YS, Choy JH, Tateyamab H. J Mater Chem 2001;11:1305-12.

[14] Ijdo WL, Pinnavaia TJ. Chem Mater 1999;11:3227-31. 
[15] Imai $\mathrm{Y}$, Nishimura S, Abe E, Tateyama H, Abiko A, Yamaguchi A, et al. Chem Mater 2002;14:477-9.

[16] Xie W, Xie R, Pan WP, Hunter D, Koene B, Tan LS, et al. Chem Mater 2002;14:4837-45.

[17] Fu X, Qutubuddin S. Polymer 2001;42:807-13.

[18] Sepehr M, Utracki LA, Zheng X, Wilkie CA. Polymer 2005;46:11557-68.

[19] Zheng X, Jiang DD, Wang D, Wilkie CA. Polym Degrad Stabil 2006;91:289-97.

[20] Theng BKG. Formation and properties of clay-polymer complexes. New York: Elsevier; 1979.

[21] Olphen HV. Clay colloid chemistry. 2nd ed. New York: John Wiley \& Sons; 1997.

[22] Pinnavaia TJ. Science 1983;220:365-71.

[23] Alexandre M, Dubois P. Mater Sci Eng R: Rep 2000;28:1-63.

[24] Zanetti M, Lomakin S, Camino G. Macromol Mater Eng 2000;279:1-9.
[25] Porter D, Metcalfe E, Thomas MJK. Fire Mater 2000;24:45-52.

[26] Fornes TD, Hunter DL, Paul DR. Macromolecules 2004;37:1793-8.

[27] Lin JJ, Chen YM. Langmuir 2004;20:4261-4.

[28] Lin JJ, Chu CC, Chiang ML, Tsai WC. J Phys Chem B 2006;110:18115-20.

[29] Usuki A, Hasegawa N, Kadoura H, Okamoto T. Nano Lett 2001;1:271-2.

[30] Lin JJ, Cheng IJ, Wang RC, Lee RJ. Macromolecules 2001;34:8832-4.

[31] Chou CC, Lin JJ. Macromolecules 2005;38:230-3.

[32] Chang YC, Chou CC, Lin JJ. Langmuir 2005;21:7023-8.

[33] Lin JJ, Hsu YC, Wei KL. Macromolecules 2007;40:1579-84.

[34] Chu CC, Chiang ML, Tsai CM, Lin JJ. Macromolecules 2005;38:6240-3. 